\title{
Wirsung atraumatic rupture in patient with pancreatic pseudocysts: a case presentation

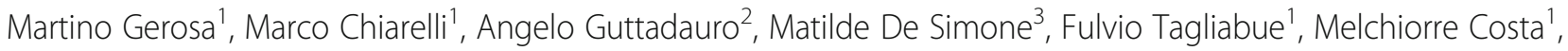
Sabina Terragni ${ }^{2}$ and Ugo Cioffi ${ }^{3 *}$

\begin{abstract}
Background: Pancreatic duct disruption is a challenging condition leading to pancreatic juice leakage and consequently to pancreatic fluid collections. The manifestations of pancreatic main duct leak include pseudocysts, walled-off necrosis, pancreatic fistulas, ascites, pleural and pericardial effusions. Pseudocyst formation is the most frequent outcome of a pancreatic duct leak.

Case presentation: We describe a case of a 64-year old man with large multiple pancreatic cysts discovered for progressive jaundice and significant weight loss in the absence of a previous episode of acute pancreatitis. Computed tomography scan showed lesion with thick enhancing walls. The main cyst dislocated the stomach and the duodenum inducing intra and extrahepatic bile ducts enlargement. Magnetic resonance cholangiopancreatography revealed a communication between the main pancreatic duct and the cystic lesions due to Wirsung duct rupture. Endoscopic ultrasound guided fine needle aspiration cytology did not show neoplastic cells and cyst fluid analysis revealed high amylase concentration. Preoperative exams were suggestive but not conclusive for a benign lesion. Laparotomy was necessary to confirm the presence of large communicating pseudocysts whose drainage was performed by cystogastrostomy. Histology confirmed the inflammatory nature of the cyst wall. Subsequently, the patient had progressive jaundice resolution.
\end{abstract}

Conclusion: Pancreatic cystic masses include several pathological entities, ranging from benign to malignant lesions. Rarely pseudocysts present as complex cystic pancreatic lesions with biliary compression in absence of history of acute pancreatitis. We describe the rare case of multiple pancreatic pseudocysts due to Wirsung duct rupture in absence of previous trauma or acute pancreatitis. Magnetic resonance showed the presence of communication with the main pancreatic duct and endoscopic ultrasound fine needle aspiration suggested the benign nature of the lesion.

Keywords: Pseudocyst, Jaundice, Pancreatic duct rupture, Acute pancreatitis, Pancreatic cystic mass

\section{Background}

Pancreatic pseudocysts are the consequence of a pancreatic duct disruption, especially as a result of acute necrotizing pancreatitis. They complicate acute pancreatitis episodes in $5 \%-15 \%$ of cases [1]. Wirsung rupture is usually associated with chronic pancreatitis or trauma [2]. The most frequent clinical presentation of pancreatic pseudocyst is abdominal pain [3], while obstructive jaundice is uncommon [4]. Pancreatic cystic mass diagnosis, in the absence of previous history or risk factors for pancreatitis, could be demanding.

\footnotetext{
*Correspondence: ugo.cioffi@guest.unimi.it

${ }^{3}$ Department of Surgery, University of Milan, Via F. Sforza 35, 20122 Milan, Italy

Full list of author information is available at the end of the article
}

We describe a case of multiple pancreatic pseudocysts presenting with jaundice in a setting of atraumatic Wirsung duct rupture without symptoms of acute pancreatitis.

\section{Case presentation}

A 64 year old man presented to our emergency department for 2 weeks jaundice and $10 \mathrm{~kg}$ weight loss in the last two months. The patient did not report previous abdominal trauma, abdominal pain or history of alcohol abuse.

An outpatient abdominal ultrasound (US) showed a complex large cystic mass in the epigastric area. The serum level of total bilirubin was $7.5 \mathrm{mg} / \mathrm{dL}$, direct bilirubin $6.0 \mathrm{mg} / \mathrm{dL}$, lipase $881 \mathrm{U} / \mathrm{L}$. The level of serum carcino-embryonic antigen (CEA) was $0.9 \mathrm{ng} / \mathrm{mL}$ (normal range 0-5.0 ng/mL), carbohydrate antigen 19-9

(c) The Author(s). 2018 Open Access This article is distributed under the terms of the Creative Commons Attribution 4.0 International License (http://creativecommons.org/licenses/by/4.0/), which permits unrestricted use, distribution, and reproduction in any medium, provided you give appropriate credit to the original author(s) and the source, provide a link to the Creative Commons license, and indicate if changes were made. The Creative Commons Public Domain Dedication waiver (http://creativecommons.org/publicdomain/zero/1.0/) applies to the data made available in this article, unless otherwise stated. 
(Ca 19-9) 17.4 U/mL (normal range 0-37 U/mL), carbohydrate antigen 125 (Ca 125) $58.9 \mathrm{U} / \mathrm{mL}$ (normal range $0-35 \mathrm{U} / \mathrm{mL}$ ), chromogranin A (CgA) $1.6 \mathrm{nmol} / \mathrm{L}$ (normal range $0.5-3.0 \mathrm{nmol} / \mathrm{L}$ ) and neuron specific enolase (NSE) $14.3 \mu \mathrm{g} / \mathrm{L}$ (normal range $0-12.5 \mu \mathrm{g} / \mathrm{L}$ ).

Triphasic multidetector computed tomography (CT) scan showed multiple pancreatic cystic lesions with thick enhancing walls and homogeneous liquid content (Fig. 1a-b). The main one, measuring $12 \mathrm{~cm}$ in diameter, involved the head of the pancreas. The lesion dislocated the stomach and the duodenum and determined intra and extrahepatic bile ducts enlargement. CT scan also showed a thickening of the mesentery root and pararenal spaces with enlargement of several loco-regional lymph nodes. Other two large (10 $\mathrm{cm}$ and $9 \mathrm{~cm}$ respectively) cystic lesions were identified in the body and the tail of the gland.

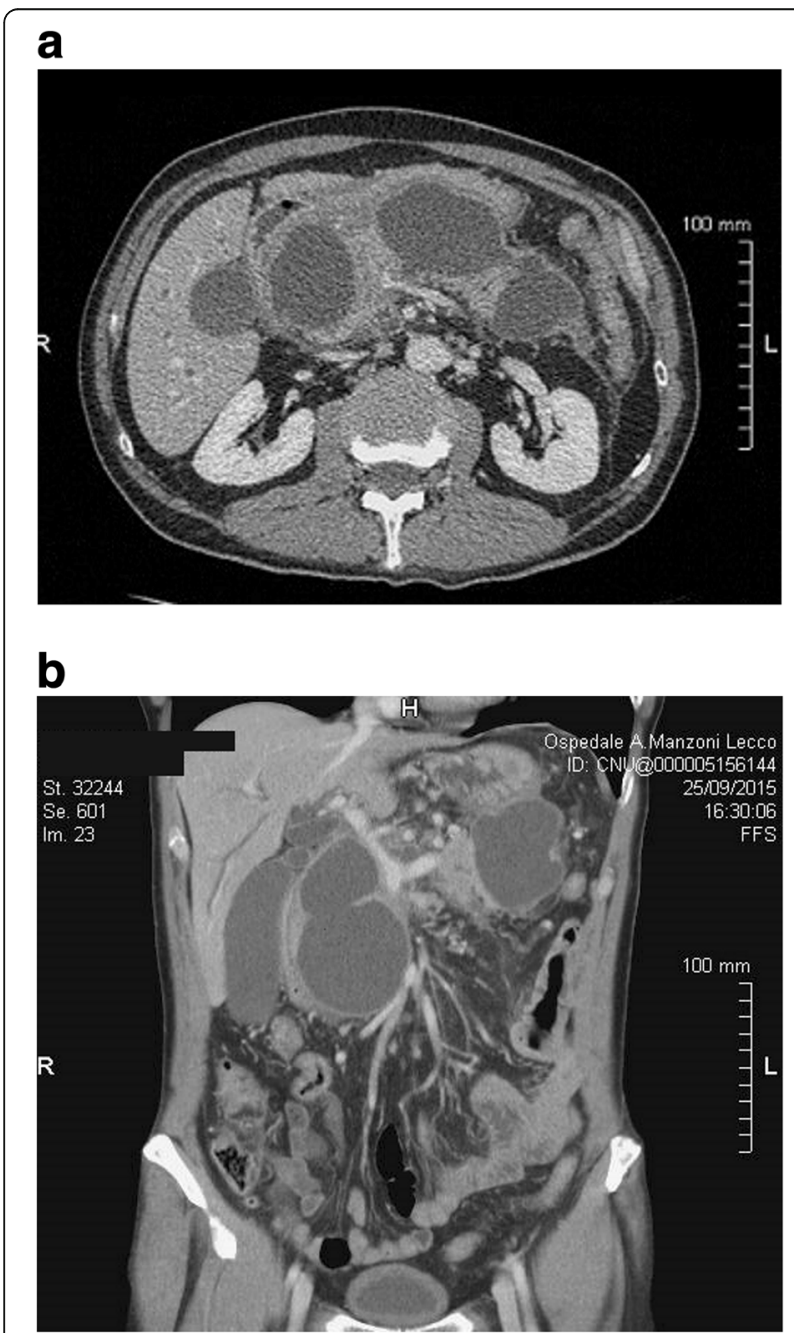

Fig. 1 a-b CT scans showed multiple defined hypodense lesions with peripheral contrast enhancing pancreatic areas compatible with cystic lesions. The main one involved the head of the pancreas and measured $12 \mathrm{~cm}$ in diameter
Moreover CT scan showed a communication between the three cystic lesions.

Magnetic resonance cholangiopancreatography (MRCP) scan confirmed the presence of large multicystic mass and revealed a communication between the main pancreatic duct and the complex lesion in the tail of the gland, suspected for Wirsung duct rupture (Fig. 2). MRCP also excluded the presence of a dilatation of the main pancreatic duct.

Endoscopic ultrasound (EUS) also confirmed the presence of a multicystic pancreatic lesion. Fine-needle aspiration cytology (FNAC) showed the presence of granulocytes, histiocytes and the absence of neoplastic cells (Fig. 3). Fluid amylase concentration was 8977 U/L; CEA was $<5 \mathrm{ng} / \mathrm{mL}$. Preoperative exams were suggestive but not conclusive for a benign lesion. Consequently an explorative laparotomy was necessary for definitive diagnosis and appropriate treatment.

Laparotomy showed diffuse mesocolic and omental calcifications with steatonecrosis as occurring in pancreatitis. A large cyst originating from the head of the pancreas dislocated the duodenum laterally and the stomach anteriorly (Fig. 4). A sampling of the liquid content of the cyst confirmed a serous fluid rich in amylase $(3132 \mathrm{U} / \mathrm{L})$. Indeed frozen section of the cyst wall pointed out the inflammatory nature of the lesion. Main cyst drainage was achieved by hand sewn cystogastrostomy.

After the procedure we observed jaundice resolution, cholestatic indexes improvement and oral intake resumption. Postoperative CT scan showed significant downsizing of the pseudocysts. The patient was discharged 15 days after the operation.

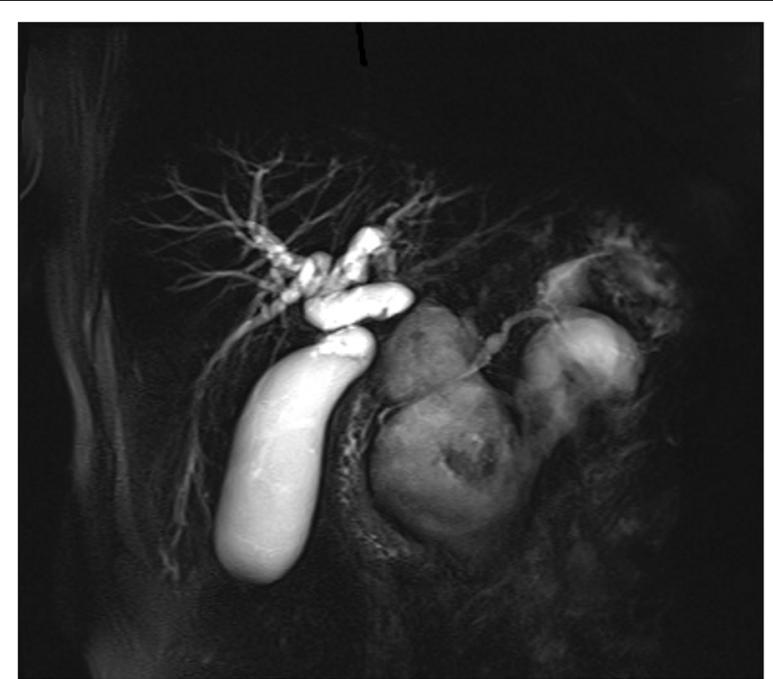

Fig. 2 MRCP scan confirmed multiple confluent pancreatic cysts. It revealed a communication between the main pancreatic duct and the cystic mass suspected for Wirsung duct rupture in the pancreatic tail 


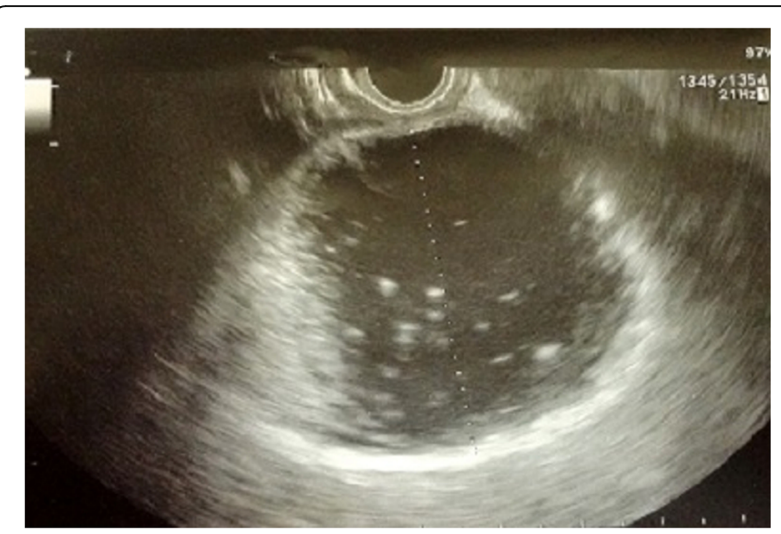

Fig. 3 EUS showed pancreatic head cystic lesion with thickened walls and serous content

\section{Discussion and conclusion}

Pancreatic duct disruption is accompanied by pancreatic juice leakage and consequently determines pancreatic fluid collections (PFCs).

The clinical manifestations of pancreatic main duct leak include pseudocysts, walled-off necrosis (WON), pancreatic fistulas, ascites, pleural and pericardial effusions [5]. According to the revised Atlanta classification, pseudocysts and WON are the late results $(>4$ weeks after pain onset) of post-pancreatitis collections $[5,6]$. Pseudocyst is the most frequent outcome of a pancreatic duct leak. WON is secondary to a focal pancreatic necrosis and is characterized by the presence of necrotic debris in the collection, while pseudocyst content is serous [6].

Disconnected duct syndrome (DDS) is a rare condition characterized by a pancreatic leak with a complete transection of the main pancreatic duct in the distal portion of the gland. It generally occurs as a result of

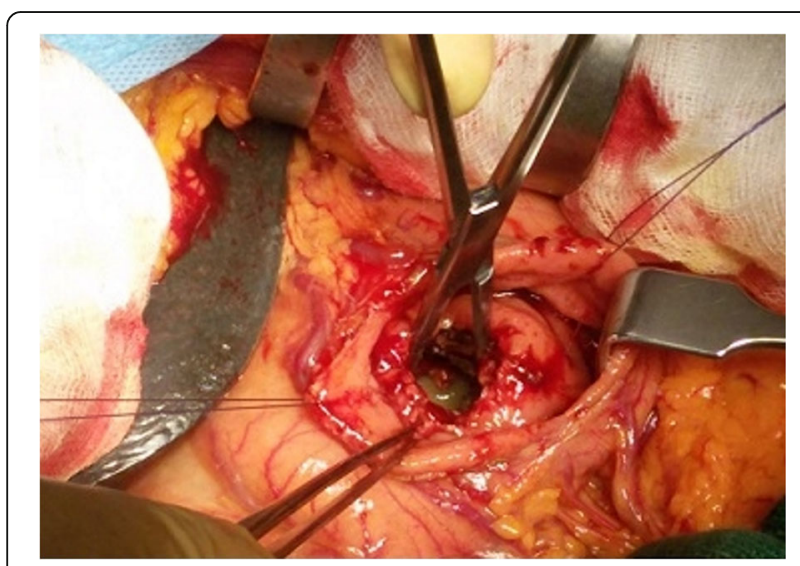

Fig. 4 Surgical view. After anterior and posterior gastric walls were opened pancreatic pseudocyst appeared and its cavity entered for drainage severe acute pancreatitis with pancreatic necrosis and can be seen in $16 \%$ of these patients [7].

$\mathrm{CT}$ and MRCP scan are the pivotal imaging exams in patients presenting with a PFC [5]. CT frequently overestimates the fluid component of a collection and may misdiagnose WON as a pseudocyst [8]. MRCP could be used as a substituted of endoscopic retrograde cholangiopancreatography (ERCP) as it can identify an active leak from a pancreatic duct [9]. EUS can be particularly helpful in identifying necrotic debris within the fluid collections [5]. EUS-FNA can be useful in differential diagnosis of cystic lesions by collecting fluid for cytology, amylase and CEA [10-12]. Pseudocyst content is usually characterized by high amylase concentration and low CEA levels. In these patients the fluid of the cyst usually contains inflammatory cells on cytologic evaluation [5]. Nevertheless cytology and fluid analysis are characterized by some limitations. In a large series FNAC showed high specificity (83\%) but low sensibility (34\%) for mucinous cystic lesions [10]. Only cyst fluid CEA concentration (cutoff value = $192 \mathrm{ng} / \mathrm{mL}$ ) was associated with remarkable specificity and sensibility (83\% and $75 \%$ respectively) for mucinous lesions [10]. Indeed, amylase concentration on cyst fluid may be elevated not only in pseudocysts but also in neoplasms with pancreatic ducts communication [13].

Our patient had no risk factors, history or signs of acute pancreatitis. No previous abdominal trauma was reported. Symptoms of presentation were jaundice onset and significant weight loss. Abdominal pain is the most frequent symptom of presentation of a pseudocyst [3]. Jaundice and weight loss occur more frequently in pancreatic neoplasms. In a large retrospective analysis, jaundice and weight loss account respectively for 3.9 and $18.6 \%$ of symptoms presentation of a pseudocyst [14]. Indeed patients developing pseudocysts are rarely asymptomatic for pancreatitis, making our diagnosis more challenging. Mucinous cystic neoplasm (MCN) and intraductal papillary mucinous neoplasm (IPMN) were considered as alternative diagnosis [15].

$\mathrm{MCNs}$ are thick-walled macrocystic tumors without ductal system communication [16-18]. Large cystic lesions detected on CT scan were coherent with MCN but MRCP findings excluded this diagnosis. IPMN was considered due to the presence of a communication between the cysts and the pancreatic ducts; however the dilation of Wirsung duct, characteristic of IPMN type main duct, was absent.

Nevertheless the lack of neoplastic cells on EUSguided FNAC and the high concentration of amylases made the diagnosis of a benign cyst more probable than a malignant lesion [16].

Management of PFCs is conservative in case of small collections, small duct defects and in the absence of ductal obstruction downstream consequent to duct disruption [6]. Large ductal disruptions with downstream 
obstruction require operative management. Nowadays only symptomatic PFCs are recommended for drainage [6]. In our case the presence of jaundice, upper gastrointestinal compression and large size of pseudocysts required drainage. Currently the drainage of a pseudocyst can be performed with a surgical or endoscopic technique: in the last decades endoscopic treatment has become the approach of choice [19].

Surgical cystogastrostomy is usually performed through an anastomosis between the lumen of the cyst cavity and the stomach [20]. Surgical drainage is an efficacious therapy. After drainage, pseudocyst recurrence rate is $2.5 \%-5 \%$, but the rate of complications can reach $30 \%$ [21].

Endoscopic treatment modalities are transmural drainage, transpapillary drainage and pancreaticoduodenostomy or gastrostomy.

Initial studies comparing surgical to endoscopic cystogastrostomy showed equivalent pseudocyst resolution and comparable complication rates [22, 23]. However, the improvement of minimally-invasive skills made the endoscopic technique the preferred initial approach. More recent studies concluded that two techniques yielded similar technical success and complication rates but endoscopic treatment had shorter length of hospital stay and lower hospital cost [24-26]. Furthermore a Cochrane review comparing surgical and endoscopic treatment modalities concluded that further studies are required on this topic [27]. A recent analysis concluded that the optimal treatment for pancreatic pseudocyst is still controversial, in the absence of meta-analysis comparing the two approaches [25].

We performed surgical exploration for three reasons. Firstly, the peritoneal exploration and the frozen section definitively could exclude the tumor nature of the cystic lesion. Moreover, the surgical drainage allowed a faster biliary and stomach decompression. Finally, a reduced experience in pseudocysts endoscopic drainage with EUS guidance at our institution made surgical treatment more reliable.

Retrospectively, in our case, the more reliable explanation of the multiple pseudocysts origin was a rupture of the main pancreatic duct secondary to an asymptomatic focal necrotic pancreatitis of the tail of the gland. The complex cystic mass was later revealed due to gastric and biliary tract compression.

Pancreatic pseudocysts generally complicate acute and symptomatic episodes of pancreatitis. In our case the presence of a complex cystic pancreatic lesion and Wirsung duct rupture in the absence of a previous episode of acute pancreatitis or abdominal trauma made the diagnosis challenging. In such cases, CT, RM and EUS are essential for suspecting malignant lesions and for defining the presence of a communication with the pancreatic ducts.

\section{Abbreviations}

CA 19-9: carbohydrate antigen 19-9; CA125: carbohydrate antigen 125; CEA: carcino-embryonic antigen; CgA: chromogranin A; CT: computed tomography; EUS-FNA: endoscopic ultrasound fine needle aspiration; EUS-FNAC: endoscopic ultrasound fine needle aspiration citology; IPMN: intraductal papillary mucinous neoplasm; MCN: mucinous cystic neoplasm; MRCP: magnetic resonance cholangiopancreatography; NSE: neuron specific enolase; PFCs: pancreatic fluid collections; US: abdominal ultrasound; WON: walled-off necrosis

\section{Acknowledgments}

We thank Dott Gerardo Cioffi native speaker for English editing.

\section{Authors' contributions}

MG: collected information of patient and wrote the contents of clinical history and the review of the literature. MC: drafted the manuscript and revised it. AG: collected information of patient and revised the contents of discussion of the manuscript. ST: collected information of patient and wrote the contents of clinical history. FT: revised the contents of the discussion and conclusions of the manuscript. MC: revised the conclusions of the manuscript; performed the surgery. MDS: revised the manuscript. UC: carried out the concept and the design of the study and revised the manuscript. All authors have read and approved the final version of the manuscript.

Ethics approval and consent to participate

Not applicable.

\section{Consent for publication}

Written informed consent was obtained from the patient for publication of this Case report and any accompanying images. A copy of the written consent is available on request.

\section{Competing interests}

None of the contributing authors have any conflict of interest, including specific financial interests or relationships and affiliations relevant to the subject matter or materials discussed in the manuscript.

\section{Publisher's Note}

Springer Nature remains neutral with regard to jurisdictional claims in published maps and institutional affiliations.

\section{Author details}

${ }^{1}$ Department of Surgery, ASST Lecco, Via dell'Eremo 9/11, 23900 Lecco, Italy. ${ }^{2}$ Department of Surgery, University of Milan-Bicocca, Istituti Clinici Zucchi, Via Zucchi 24, 20900 Monza, Italy. ${ }^{3}$ Department of Surgery, University of Milan, Via F. Sforza 35, 20122 Milan, Italy.

Received: 18 November 2017 Accepted: 17 April 2018

Published online: 23 April 2018

\section{References}

1. Poornachandra KS, Bhasin DK, Nagi B, Sinha SK, Rana SS, Shafig N, et al. Clinical, biochemical, and radiologic parameters at admission predicting formation of a pseudocyst in acute pancreatitis. J Clin Gastroenterol. 2011;45:159-63.

2. Varadarajulu S, Rana S, Bhasin D. Endoscopic therapy for pancreatic duct leaks and disruptions. Gastrointest Endosc Clin N Am. 2013;23:863-92.

3. Gumaste W, Pitchumoni CS. Pancreatic pseudocyst. Gastroenterologist. 1996;4:33-43.

4. Warshaw AL, Facts RDW. Fallacies of common bile duct obstruction by pancreatic pseudocysts. Am J Surg. 1980;192:33-7.

5. Larsen M, Kozarek R. Management of pancreatic ductal leaks and fistulae. J Gastroenterol Hepatol. 2014;29:1360-70.

6. Banks PA, Bollen TL, Dervenis C, Gooszen HG, Johonson CD, Sarr MG, et al. Acute pancreatitis classification working group. Classification of acute pancreatitis-2012: revision of the Atlanta classification and definitions by international consensus. Gut. 2013;62:102-11.

7. Varadarajulu S, Wilcox CM. Endoscopic placement of permanent indwelling transmural stents in disconnected pancreatic duct syndrome: does benefit outweigh the risks? Gastrointest Endosc. 2011;74:1408-12. 
8. Baron TH, Morgan DE. Acute necrotizing pancreatitis. N Engl J Med. 1999; 340:1412-7.

9. Gillams AR, Kurzawinski T, Lees WR. Diagnosis of duct disruption and assessment of pancreatic leak with dynamic secretin-stimulated MR cholangiopancreatography. AJR Am J Roentgenol. 2006;186:499-506.

10. Brugge WR, Lewandrowski K, Lee-Lewandrowski E, Centeno BA, Szydio T, Regan S, et al. Diagnosis of pancreatic cystic neoplasms: a report of the cooperative pancreatic cyst study. Gastroenterology. 2004;126:1330-6.

11. Petrone MC, Arcidiacono PG. Role of endoscopic ultrasound in the diagnosis of cystic tumours of the pancreas. Dig Liv Dis. 2008;40:847-53.

12. Chiarelli M, Gerosa M, Tagliabue F, Fumagalli L, Guttadauro A, Gabrielli F, et al. Left-sided pancreatic incidentalomas treated with laparoscopic approach: a report of 20 cases. World J Surg Oncol. 2016;14(1):204.

13. Kadiyala V, Lee LS. Endosonography in the diagnosis and management of pancreatic cysts. World J Gastrointest Endosc. 2015 March 16;7(3):213-23.

14. Rasch S, Notzel B, Phillip V, Lahmer T, Schmid RM, Algul H. Management of pancreatic pseudocysts-a retrospective analysis. PLoS One. 2017;12(9): e0184374.

15. Shohat S, Shulman K, Kessel B, Gal O, Zeina AR. Rupture of main pancreatic duct with multi-focal pancreatic adenocarcinoma. J Clin and Diagn Res. 2016;10(12):-PD15-PD17.

16. Adsay VN. Cystic lesions of the pancreas. Mod Pathol. 2007;20(Suppl 1):S71-93.

17. Sarr MG, Carpenter HA, Clinical PLP. Pathologic correlation of 84 mucinous cystic neoplasms of the pancreas: can one reliably differentiate benign from malignant (or premalignant) neoplasms? Ann Surg. 2000;231:205-12.

18. Chiarelli M, Guttadauro A, Gerosa M, Marando A, Gabrielli F, De Simone M, et al. An indeterminate mucin-producing cystic neoplasm containing an undifferentiated carcinoma with osteoclast-like giant cells: a case report of a rare association of pancreatic tumors. BMC Gastroenterol. 2015;18(15):161.

19. Braden B, Dietrich CF. Endoscopic ultrasonography-guided endoscopic treatment of pancreatic pseudocysts and walled off necrosis: new techinical developments. World J Gastroenterol. 2014 Nov 21;20(43):16191-6.

20. Li JY. Yu T, Chen GC et al. enteral nutrition within 48 hours of admission improves clinical outcomes of acute pancreatitis by reducing complications: a meta-analysis. PLoS One. 2013;8(6):e64926.

21. Parks RW, Tzovaras G, Diamond T, Rowlands BJ. Management of pancreatic pseudocysts. Ann R Coll Surg Engl. 2000;82:383-7.

22. Johnson MD, Walsh RM, Henderson JM, et al. Surgical versus nonsurgical management of pancreatic pseudocysts. J Clin Gastroenterol. 2009:43:586-90

23. Melman L, Azar R, Beddow K, Brunt LM, Halpin VJ, Eagon JC, et al. Primary and overall success rates for clinical outcomes after laparoscopic, endoscopic, and open pancreatic cystgastrostomy for pancreatic pseudocysts. Surg Endosc. 2009;23:267-71.

24. Varadarajulu S, Bang JY, Sutton BS, Trevino JM, Christein JD, Wilcox CM. Equal efficacy of endoscopic and surgical cystogastrostomy for pancreatic pseudocyst drainage in a randomized trial. Gastroenterology. 2013;145:583-90.

25. Zhao X, Feng T, Ji W. Endoscopic versus surgical treatment for pancreatic pseudocyst. Dig Endosc. 2016;28:83-91.

26. Saul A, Ramirez Luna MA, Chan C, Usganga L, Valdovinos Andraca F, Hernandez Callero J, et al. EUS-guided drainage of pancreatic pseudocysts offers similar success and complications compared to surgical treatment but with a lower cost. Surg Endosc. 2016;30:1459-65.

27. Gurusamy KS, Pallari E, Hawkins N, Pereira SP, Davidson BR. Management strategies for pancreatic pseudocysts. Cochrane Database Syst Rev. 2016;14:4. CD011392.

\section{Ready to submit your research? Choose BMC and benefit from:}

- fast, convenient online submission

- thorough peer review by experienced researchers in your field

- rapid publication on acceptance

- support for research data, including large and complex data types

- gold Open Access which fosters wider collaboration and increased citations

- maximum visibility for your research: over $100 \mathrm{M}$ website views per year

At BMC, research is always in progress.

Learn more biomedcentral.com/submissions 